\title{
Adsorption of sulfamethoxazole by wheat straw-derived biochars in seawater
}

\author{
Man Zhao ${ }^{1,2}$, Mengying Shao ${ }^{1}$, Xiaohan $\mathrm{Ma}^{1, *}$ \\ ${ }^{1}$ Institute of Coastal Environmental Pollution Control, Key Laboratory of Marine Environment and Ecology, Ministry of Education, \\ Ocean University of China, 266100 Qingdao, China \\ ${ }^{2}$ College of Ecology and Environment, Hainan Tropical Ocean University, 572000 Sanya, China
}

\begin{abstract}
The excessive use of antibiotics in mariculture have resulted in high pollution burdens of antibiotics in marine environment. Biochars, as promising adsorbents, have been widely used in organic pollutant adsorption because of their good adsorption performance and stability. However, adsorption characteristic of antibiotics in seawater by biochar is not well known. Thus, the batch experiment for the adsorption of sulfamethoxazole (SMX) was conducted using wheat straw-derived biochars and graphite (GR) under different initial concentration of SMX and different addition of adsorbent in seawater. The results showed that the wheat straw-derived biochars produced at $700{ }^{\circ} \mathrm{C}$ was the optimal adsorbent with the maximum removal rate $(R)$ of $70.3 \%$, the maximum adsorption capacity $\left(Q_{e}\right)$ of $1.03 \mathrm{mg} \mathrm{g}^{-1}$ and the maximum adsorption coefficient $\left(K_{d}\right)$ of $0.182 \mathrm{~L} \mathrm{~g}^{-1}$. The $Q_{e}$ values increased with increasing the initial concentration of SMX, while $R$ and $K_{d}$ values of SMX decreased. The $R$ values of SMX increased with the increasing dosage of adsorbents, while $Q_{e}$ and $K_{d}$ values of SMX decreased. These findings will shed new light on the environmentally-friendly and low-cost adsorbent for controlling the antibiotic pollution in marine environment.
\end{abstract}

\section{Introduction}

The rapid development of mariculture industry has met the growing demand for animal protein in domestic and foreign markets and is an important part of the national food security strategy. Antibiotics have been widely used in mariculture in order to prevent and control bacterial diseases and promote animal growth [1]. However, due to the lack of fully understanding of disease prevention and control by fish farmers, the excessive use and even abuse of antibiotics is very serious. Overuse of antibiotics could lead to the persistence of antibiotics in environment. The persistent occurrence of residual antibiotics could pose a threat to non-target organisms [2], induce antibiotic resistance genes [3]. Therefore, measures to control antibiotic contamination in marine environment are urgently needed.

Biochar is a carbon-rich porous material, usually produced from the pyrolysis of biomass under oxygenlimited conditions [4]. Biochars have become one of the most widely used adsorption materials in the world because of their large specific surface area, high porosity, developed pore structure and abundant surface functional groups [4]. Graphite, a kind of allotrope of carbon, is a stack of graphene sheets bound by van der Waals interactions [5]. GR, which has good electrical conductivity and stable chemical properties, was an important nonporous, polar functionality-free carbonaceous sorbent. The adsorption mechanisms of biochars for sulfamethoxazole (SMX), a typical veterinary antibiotic, in freshwater mainly includes pore filling, hydrogen bonding, hydrophobicity, etc [6]. However, adsorption characteristic of antibiotics in seawater by biochar is not well known.

Therefore, this study was conducted to analyse the adsorption of SMX using biochars and GR under different initial concentration of SMX and different addition of adsorbent in seawater.

\section{Materials and methods}

\subsection{Experimental materials}

SMX was purchased from Sigma-Aldrich (USA). Molecular structure of SMX is presented in Fig. 1 [7]. The commercially available wheat straw-derived biochars and GR were select. The wheat straw-derived biochars were produced at $550{ }^{\circ} \mathrm{C}$ (WS550) and $700{ }^{\circ} \mathrm{C}$ (WS700) form the UK Biochar Research Centre at the University of Edinburgh. The biochar properties had been reported before [8]. GR was purchased from Hebei Huiji Material Co., Ltd of China. 


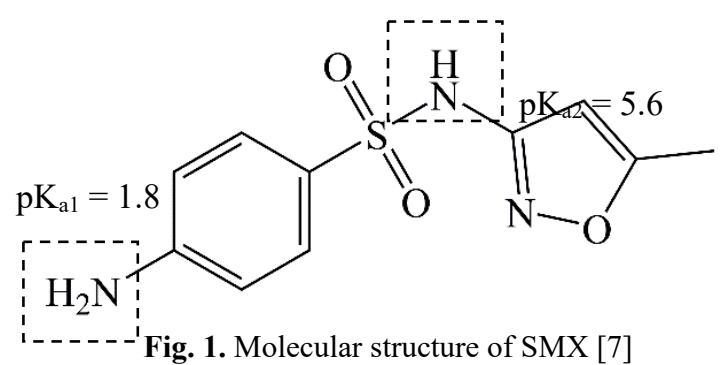

\subsection{Adsorption experiments}

The adsorption experiments of SMX by WS550, WS700 and GR were carried out with different added amount under different SMX concentrations. SMX stock solution (100 $\left.\mathrm{mg} \mathrm{L}^{-1}\right)$ with natural seawater as background solution was prepared. Natural seawater, which salinity and $\mathrm{pH}$ were $31.6 \%$ and $8.0 \pm 0.02$, was filtered immediately through $0.22 \mu \mathrm{m}$ pore size polyethersulfone membrane. SMX solution was diluted with seawater to $0.5,5$ and $50 \mathrm{mg} \mathrm{L}^{-1}$. Biochars or GR $(25,50$, and $100 \mathrm{mg})$ were added into $8 \mathrm{~mL}$ glass vials containing $7 \mathrm{~mL}$ SMX solution. $\mathrm{NaOH}$ or $\mathrm{HCl}$ were used to pre-adjust the $\mathrm{pH}$ of SMX solution to ensure the desirable $\mathrm{pH} 8.0$ at sorption equilibrium. The glass vials without materials were set as the control. Each of the samples had triplicates. All the vials were shaken at 150 rpm and $25{ }^{\circ} \mathrm{C}$ in the dark for 48 hours. The sediment samples were centrifuged at $3500 \mathrm{rpm}$ for $30 \mathrm{~min}$ to obtain the supernatants for determining SMX concentration using Agilent 1260 liquid chromatography (HPLC, 1260, Agilent, USA). Detection method was previously reported [9].

\subsection{Statistical analysis}

Removal rates, adsorption capacities and adsorption coefficients were calculated by the following equations, respectively.

$$
\begin{gathered}
R=\left(C_{0}-C_{e}\right) / C_{0} \\
Q_{e}=\left(C_{0}-C_{e}\right) V / m \\
K_{d}=Q_{e} / C_{e}
\end{gathered}
$$

Where $R$ were removal rates (\%); $C_{0}$ and $C_{e}$ were the initial and equilibrium aqueous concentrations of SMX $\left(\mathrm{mg} \mathrm{L}^{-1}\right)$, respectively; $Q_{e}$ were adsorption capacities (mg $\left.\mathrm{g}^{-1}\right) ; V$ were volume of solution (L); $m$ was sample mass of WS550, WS700 and GR $(\mathrm{g}) ; K_{d}$ were adsorption coefficients. Significant differences were analysed using Statistical Product and Service Solutions Software (SPSS 21.0). Different lowercase letters indicate significant difference for the different treatments using One-way analysis of variance (ANOVA).

\section{Results and discussion}

\subsection{Removal rate of SMX}

The $R$ of SMX on the WS550, WS700 and GR were shown in Fig. 2. As the dosage of WS550, WS700 and GR increased from 25 to $100 \mathrm{mg}$, the $R$ of SMX also increased from $5.89-25.9 \%$ to $10.7-49.2 \%, 7.65-37.7 \%$ to $12.0-70.3 \%$ and $3.79-7.12 \%$ to $9.16-20.0 \%$. Those results indicated the $R$ of SMX increased with increasing addition of materials, which is showed that the increase in the amount of materials provided more adsorption sites for SMX [10]. As the initial concentration of SMX increased from 0.5 to $50 \mathrm{mg} \mathrm{L}^{-1}$, the $R$ of SMX decreased
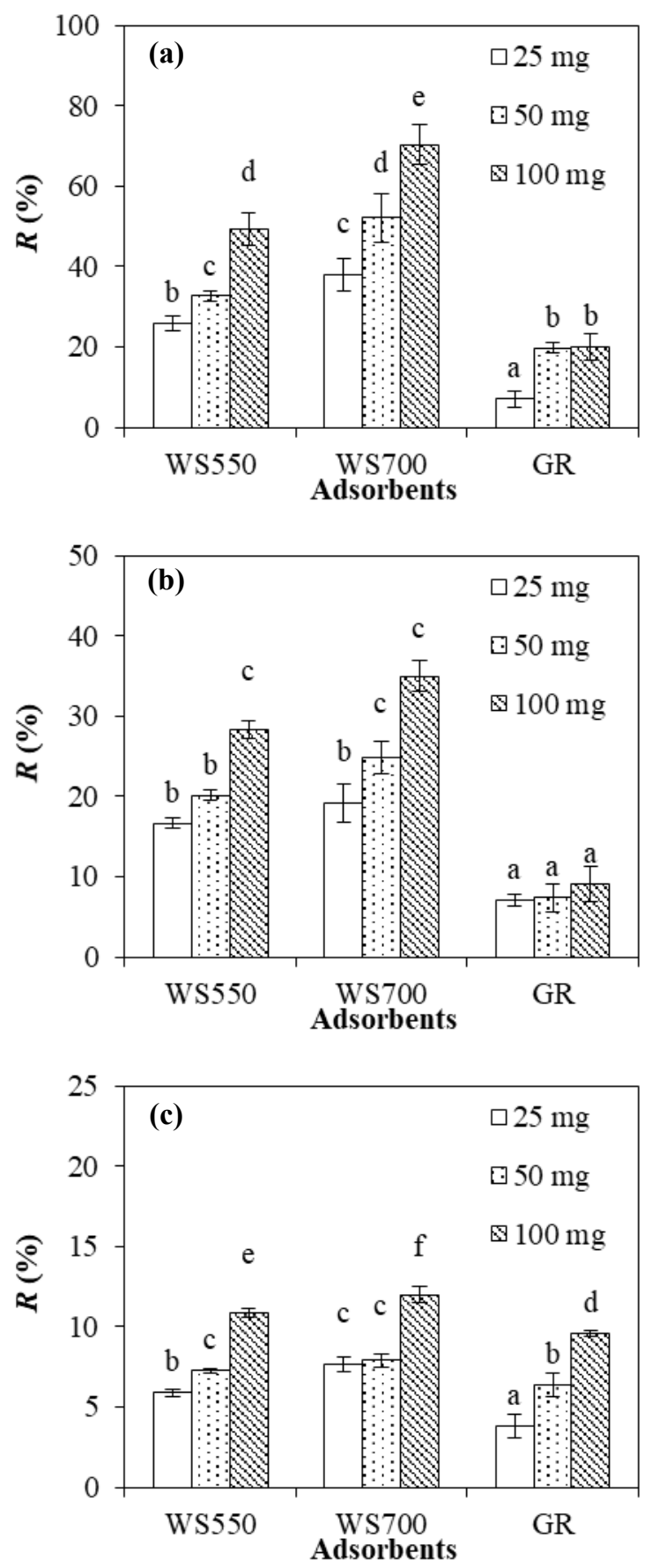

Fig. 2. The $R$ of SMX on WS550, WS700 and GR under different initial SMX concentration of 0.5 (a), 5 (b) and $50 \mathrm{mg}$ 
$\mathrm{L}^{-1}(\mathrm{c})$ and different addition of adsorbent. WS550 and WS700: The wheat straw-derived biochars were produced at 550 and $700{ }^{\circ} \mathrm{C}$. GR: Graphite.

from $25.9-49.2 \%$ to $5.89-10.9 \%$ for WS550 addition, from $37.9-70.3 \%$ to $7.65-12.0 \%$ for WS700 addition and from $7.12-20.0 \%$ to $3.79-9.60 \%$ for GR addition. Those results indicated the $R$ of SMX decreased with increasing the initial aqueous concentration of SMX, which was showed that the adsorption of SMX was becoming saturate [11]. In addition, $R$ of SMX on the materials showed the order of WS700 $>$ WS500 $>$ GR.

\subsection{Adsorption capacity of SMX}

The $Q_{e}$ of SMX on the WS550, WS700 and GR were shown in Fig. 3. As the dosage of WS550 and WS700 increased from 25 to $100 \mathrm{mg}$, the $Q_{e}$ of SMX decreased from $0.035-0.803 \mathrm{mg} \mathrm{g}^{-1}$ to $0.017-0.407 \mathrm{mg} \mathrm{g}^{-1}$ and $0.052-1.034 \mathrm{mg} \mathrm{g}^{-1}$ to $0.024-0.416 \mathrm{mg} \mathrm{g}^{-1}$. The $Q_{e}$ of SMX decreased from $0.014-0.437 \mathrm{mg} \mathrm{g}^{-1}$ to $0.007-0.327$ $\mathrm{mg} \mathrm{g}^{-1}$ with increasing the addition of GR from 50 to 100 $\mathrm{mg}$. Those results indicated the $Q_{e}$ of each material decreased with the increase of the addition of materials under the same initial concentration of SMX. This may be because the active adsorption sites on the surface of materials have a lager chance to completely contact with SMX molecules when the addition of materials is low. However, aggregation of materials may occur, leading reduce of the active adsorption sites and $Q_{e}$ when the addition of materials reached high levels. As the initial concentration of SMX increased from 0.5 to $50 \mathrm{mg} \mathrm{L}^{-1}$, the $Q_{e}$ of SMX also increased from $0.017-0.035 \mathrm{mg} \mathrm{g}^{-1}$ to $0.417-0.803 \mathrm{mg} \mathrm{g}^{-1}$ for WS550 addition, from 0.024 $0.052 \mathrm{mg} \mathrm{g}^{-1}$ to $0.416-1.034 \mathrm{mg} \mathrm{g}^{-1}$ for WS700 addition and from $0.007-0.010 \mathrm{mg} \mathrm{g}^{-1}$ to $0.327-0.519 \mathrm{mg} \mathrm{g}^{-1}$ for GR addition. Those results indicated the as the initial concentration of SMX increased by one order of magnitude, the $Q_{e}$ of each material also increases by one order of magnitude. Because with increasing of SMX concentration in the solution, SMX concentration gradient between liquid and solid phases was increased, and the driving force of adsorption was also enhanced, leading SMX molecules were more likely to diffuse into the pores of the materials. This also indicates that there still exist adsorption sites on the surface of adsorbents. Furthermore, $Q_{e}$ of SMX on the materials showed the order of WS700 > WS500 > GR.

\subsection{Adsorption coefficient of SMX}

The $K_{d}$ of SMX on the WS550, WS700 and GR were shown in Fig. 3. As the dosage of WS550 and WS700 increased from 25 to $100 \mathrm{mg}$, the $K_{d}$ of SMX decreased from $0.017-0.096 \mathrm{~L} \mathrm{~g}^{-1}$ to $0.008-0.067 \mathrm{~L} \mathrm{~g}^{-1}$ and $0.022-$ $0.182 \mathrm{~L} \mathrm{~g}^{-1}$ to $0.009-0.126 \mathrm{~L} \mathrm{~g}^{-1}$. The $K_{d}$ of SMX decreased from $0.010-0.021 \mathrm{~L} \mathrm{~g}^{-1}$ to $0.007-0.017 \mathrm{~L} \mathrm{~g}^{-1}$ with increasing the addition of GR from 50 to $100 \mathrm{mg}$. This was consistent with the previous conclusion, which with increased of materials addition, the $Q_{e}$ decreased and the $K_{d}$ also decreased. As the initial concentration of SMX increased from 0.5 to $50 \mathrm{mg} \mathrm{L}^{-1}$, the $K_{d}$ of SMX also increased from $0.067-0.096 \mathrm{~L} \mathrm{~g}^{-1}$ to $0.008-0.017 \mathrm{~L}$ $\mathrm{g}^{-1}$ for WS550 addition, from $0.126-0.182 \mathrm{~L} \mathrm{~g}^{-1}$ to
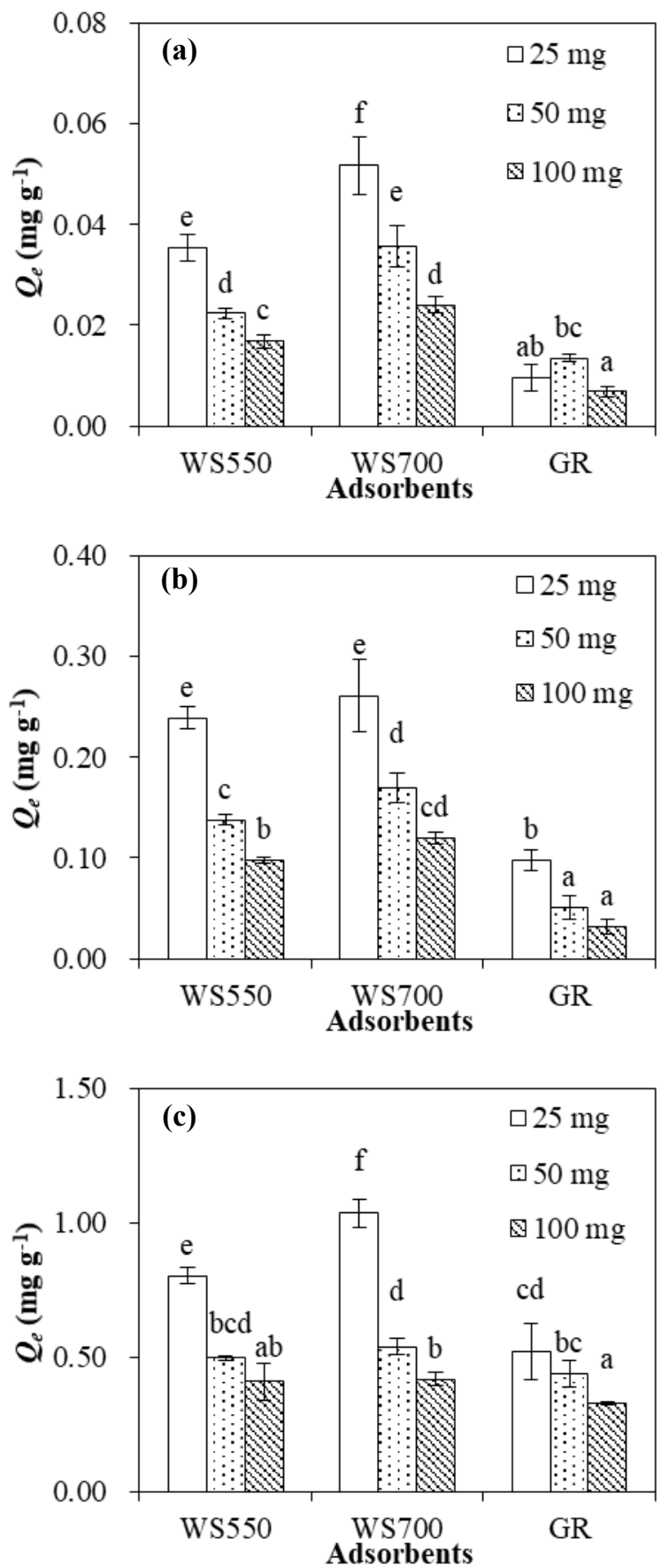

Fig. 3. The $Q_{e}$ of SMX on WS550, WS700 and GR under different initial SMX concentration of 0.5 (a), 5 (b) and $50 \mathrm{mg}$ $\mathrm{L}^{-1}(\mathrm{c})$ and different addition of adsorbent. WS550 and WS700: The wheat straw-derived biochars were produced at 550 and $700{ }^{\circ} \mathrm{C}$. GR: Graphite.

0.009-0.022 $\mathrm{L} \mathrm{g}^{-1}$ for WS700 addition and from 0.017$0.034 \mathrm{~L} \mathrm{~g}^{-1}$ to $0.007-0.012 \mathrm{~L} \mathrm{~g}^{-1}$ for GR addition. This was also consistent with the previous conclusion. Although WS550, WS700 and GR would adsorb SMX, the adsorption affinity would decrease due to lack of enough adsorption sites with increased the initial concentration of SMX. Moreover, $K_{d}$ of SMX on the materials showed the order of WS700 $>$ WS500 $>$ GR. 

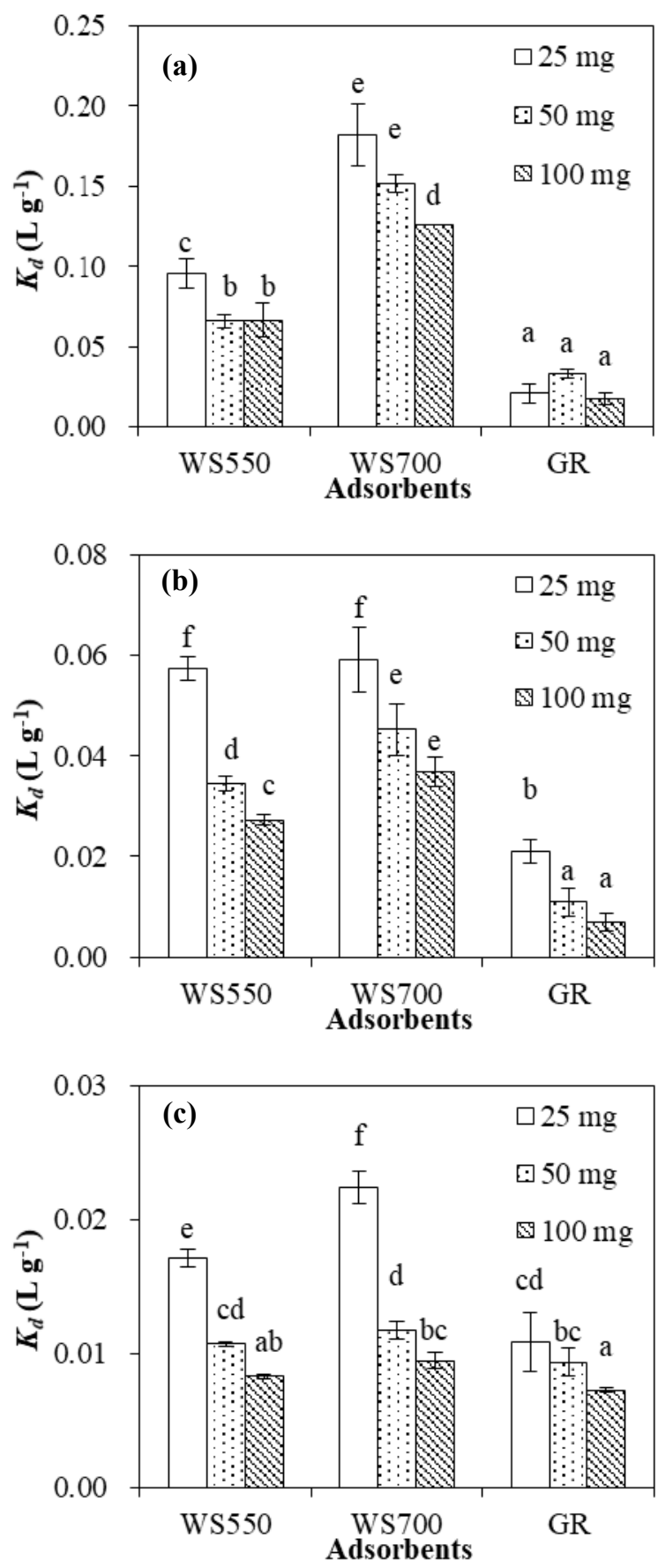

Fig. 4. The $K_{d}$ of SMX on WS550, WS700 and GR under different initial SMX concentration of 0.5 (a), 5 (b) and $50 \mathrm{mg}$ $\mathrm{L}^{-1}(\mathrm{c})$ and different addition of adsorbent. WS550 and WS700 The wheat straw-derived biochars were produced at 550 and $700{ }^{\circ} \mathrm{C}$. GR: Graphite.

\subsection{Potential adsorption mechanisms}

Compared with GR, WS550 and WS700 have stronger adsorption capacities. On the one hand, the abundant pore structure and large surface area of WS550 and WS700 provided more adsorption sites for SMX, while GR with non-porous lamellar structure has fewer adsorption sites [12]. On the other hand, positively charged ions (e.g., $\mathrm{Mg}^{2+}, \mathrm{Ca}^{2+}, \mathrm{K}^{+}$and $\mathrm{Na}^{+}$) in seawater can increase the adsorption of ionizable organic compounds (e.g., SMX) on the adsorbent surface through cation bridging [13].

\section{Conclusions}

Highly efficient, environmentally-friendly and low-cost adsorbent is needed to control antibiotic contamination in seawater. The findings of this study revealed that the adsorption performance of carbonaceous materials for SMX was as follows: WS700 > WS500 > GR. Wheat straw-derived biochars can adsorb antibiotics effectively. With increased the initial concentration of SMX, $Q_{e}$ values of SMX would increase, while $R$ and $K_{d}$ values of SMX would decrease. With increased the dosage of adsorbent, the $R$ values of SMX would increase, while $Q_{e}$ and $K_{d}$ values of SMX would decrease. Our findings provide a promising information for selecting suitable materials to remove antibiotic in marine environment.

\section{Acknowledgment}

This study was supported by the Shandong Province Natural Science Foundation (ZR2019MD017).

\section{References}

1. Y. Mo, Z. Chen, H. Leung, A. O. Leung, Environ. Sci. Pollut. Res 24, 8978-8989 (2017).

2. G. He, X. Jiang, L. Yao, G. Liu, Y. Yang, Y. Jiang, W. Liu, Chemosphere 270, 129509 (2020).

3. M. Reverter, S. Sarter, D. Caruso, J. C. Avarre, M. Combe, E. Pepey, L. Pouyaud, S. Vega-Heredia, H. de Verdal, R.E. Gozlan, Nat. Commun 11, 1870 (2020).

4. X. Xiao, B. Chen, Z. Chen, L. Zhu, J.L. Schnoor, Environ. Sci. Technol 52, 5027-5047 (2018).

5. E. Bordes, B. Morcos, D. Bourgogne, J.M. Andanson, P.O. Bussiere, C.C. Santini, A. Benayad, M. Costa Gomes, A.A.H. Padua, Front. Chem 7, 223 (2019).

6. F. Lian, B. Sun, Z. Song, L. Zhu, X. Qi, B. Xing, Chem. Eng. J 248, 128-134 (2014).

7. L. Ji, Y. Wan, S. Zheng, D. Zhu, Environ. Sci. Technol 45, 5580-5586 (2011).

8. O. Mašek, W. Buss, S. Sohi, Environ. Sci. Technol 52, 9543-9545 (2018).

9. H. Zheng, Z. Wang, J. Zhao, S. Herbert, B. Xing, Environ. Pollut 181, 60-67 (2013).

10. S. Bai, C. Jin, S. Zhu, F. Ma, L. Wang, Q. Wen, J. Hazard. Mater 409, 125024 (2021).

11. B. Chen, D. Zhou, L. Zhu, Environ. Sci. Technol 42, 5137-5143 (2008).

12. W. Chen, J. Ni, Chemosphere 175, 323-331 (2017).

13. M. Kah, G. Sigmund, F. Xiao, T. Hofmann, Water Res 124, 673-692 (2017). 